\title{
IDENTIFICAÇÃO SOROLÓGICA DO VÍRUS DO MOSAICO DAS NERVURAS DA VIDEIRA NO BRASIL*
}

\author{
HUGO KUNIYUKI ${ }^{1 * *}$, JORGE A. M. REZENDE ${ }^{2 * *}$, VALDIR A. YUKI ${ }^{1 * *} \&$ JUAREZ A. BETTI \\ ${ }^{1}$ Centro de Fitossanidade/Virologia, Instituto Agronômico, Cx. Postal 28, CEP 13020-902, Campinas, SP, \\ e-mail: hkuniyuk@ cec.iac.br; ${ }^{2}$ Departamento de Entomologia, Fitopatologia e Zoologia Agrícola , \\ ESALQ/USP, Cx. Postal 9, CEP 13418-900, Piracicaba, SP
}

(Aceito para publicação em 10/09/2002)

Autor para correspondência: Hugo Kuniyuki

KUNIYUKI, H., REZENDE, J.A.M., YUKI, V.A. \& BETTI, J.A. Identificação sorológica do vírus do mosaico das nervuras da videira no Brasil. Fitopatologia Brasileira 27:635-638. 2002.

\section{RESUMO}

Em São Paulo, ocorrem quatro isolados do vírus que induz o mosaico das nervuras da videira (Vitis spp.), os quais são diferenciados pelos sintomas que provocam em algumas variedades. Para confirmar a identidade desse vírus e o relacionamento existente entre os quatro isolados, foram aplicados os testes DAS-ELISA e TAS-ELISA usando anti-soros comerciais contra o Grapevine fleck virus (GFkV). As fontes de antígeno foram tecidos de floema de ramos dormentes e de folhas jovens da brotação de primavera de videiras sabidamente infetadas. As reações nos testes imunoenzimáticos envolvendo os quatro isolados do vírus foram positivas para o anti-soro contra o GFkV. Os resultados foram também positivos para amostras de 66 plantas infetadas de 26 variedades de videira procedentes de 11 regiões vitícolas de São Paulo e de 24 plantas de 12 variedades provenientes dos estados de Minas Gerais, Paraná, Pernambuco, Rio Grande do Norte e Santa Catarina. Extratos de folhas novas e tenras apresentaram valores de absorbância mais consistentes do que extratos de ramos dormentes. Plantas não infetadas foram empregadas como controle negativo. Os resultados obtidos confirmaram que os quatro isolados virais possuem relacionamento sorológico com o $\mathrm{GFkV}$, sugerindo que os mesmos pertencem ao complexo viral que causa o "grapevine fleck disease".

Palavras-chave adicionais: Vitis spp., Grapevine fleck virus.

\section{ABSTRACT \\ Serological identification of the Grapevine fleck virus in Brazil}

In the State of São Paulo, four different isolates of the virus that induces chlorotic translucent vein break in the minor veins of grapevines (Vitis spp.) were separated by their differential biological behaviour and tested for their relationship to Grapevine fleck virus (GFkV) by DAS-ELISA and TAS-ELISA with commercial antisera against GFkV. Young leaves from spring shoots and dormant cuttings were used for antigen extraction. All infected plants were previously indexed by graftinoculation to 'Rupestris du Lot'. The four isolates gave positive reactions to the GFkV antiserum. Positive ELISA reactions were observed in 66 samples of 26 varieties, from 11 grape-growing areas from the State of São Paulo as well as 24 samples, of 12 varieties, from five other states of Brazil. Healthy plants consistently gave negative results. Young leaves were better sources of antigen than cortical scrapings of dormant cuttings. The results showed that the four isolates have a serological relationship with the GFkV, suggesting that they belong to the viral complex that induce grapevine fleck disease.
A virose, caracterizada por sintomas de mosaico das nervuras em videira (Vitis spp.), ocorre de maneira generalizada nas regiões vitícolas do Brasil (Kuhn, 1992; Kuniyuki \& Costa, 1987, 1995). Essa doença, com base nos sintomas causados em videira indicadora, tem sido considerada semelhante ao "grapevine fleck disease", virose já descrita em outros países (Hewitt et al., 1972). Os sintomas característicos das duas doenças são evidenciados no portaenxerto de videira 'Rupestris du Lot' ('St. George') pela presença de palidez das nervuras de terceira e quarta ordens, de um a três milímetros de comprimento, de folhas jovens e médias, durante a fase de brotação de primavera (Hewitt $e t$

\footnotetext{
* Apoio financeiro PRONEX

** Bolsistas do CNPq
}

al., 1972; Kuhn, 1992; Kuniyuki \& Costa, 1994).

O "grapevine fleck disease" é induzido por um vírus de partículas isométricas de ca. $30 \mathrm{~nm}$ de diâmetro, denominado Grapevine fleck virus (GFkV) (Boscia et al., 1991), o qual é limitado ao floema e não é transmitido mecanicamente. Sua classificação taxonômica ainda não está definida, embora possua algumas características encontradas em espécies dos gêneros Tymovirus e Marafivirus (Martelli, 2000; Sabanadzovic et al., 2000). O GFkV tem sido detectado por meio de métodos sorológicos e moleculares (Boscia et al., 1991; Sabanadzovic et al., 1996).

Em São Paulo, ocorrem quatro isolados do vírus do mosaico das nervuras da videira que, apesar de causarem os sintomas típicos de palidez das nervuras em 'Rupestris du Lot' (Figura 1A), são diferenciados pela sintomatologia 
H. Kuniyuki et al.
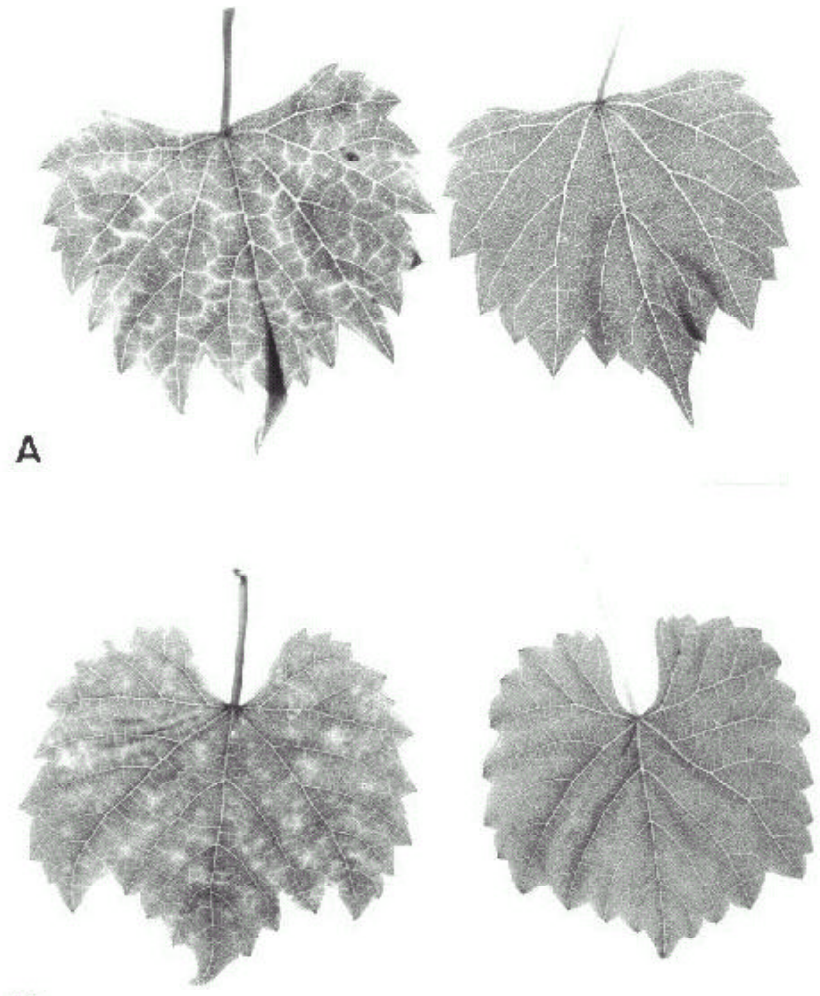

B

FIG. 1 - Sintomas de palidez das nervuras induzidos pelo isolado comum do vírus causador do mosaico das nervuras da videira (Vitis spp.). A - Folhas do porta-enxerto 'Rupestris du Lot' (à direita, folha de planta sadia). B - Folha do porta-enxerto 'Kober 5BB' (à direita, folha de planta sadia).

observada em outras variedades de videira ou pela intensidade dos sintomas. São eles: (a) isolado comum (C), assim denominado por ser o mais freqüente dentro dos vinhedos paulistas, causa sintomas evidentes no porta-enxerto Kober 5BB, mas não na variedade Kyoho (Figura 1B); (b) isolado Itália (I), obtido inicialmente de plantas assintomáticas da variedade Itália, também de ocorrência generalizada, não induz sintomas em 'Kober 5BB' e 'Kyoho'; (c) isolado obtido da variedade Kyoho $(\mathrm{K})$, que provoca sintomas de palidez das nervuras em 'Kyoho', mas não em 'Kober 5BB' e (d) isolado fraco $(\mathrm{F})$, obtido de uma planta sem sintomas de uva Itália, causa reações bastante fracas em 'Rupestris du Lot', tanto no número de manchas como na intensidade dos sintomas, quando comparadas com as induzidas pelo isolado Itália, mas não provoca alterações em 'Kober 5BB' e 'Kyoho' (Kuniyuki \& Costa, 1994; 1995).

$\mathrm{O}$ vírus que induz o mosaico das nervuras causa infecção latente na maioria das variedades de videira de importância econômica no Brasil e em outros países. As perdas causadas pelo vírus ainda não foram relatadas, mas sabe-se que o patógeno reduz o vigor das plantas infetadas de algumas variedades de copa e de porta-enxerto, como também altera a intensidade da coloração dos frutos (Kuniyuki \&
Costa, 1994)

Para confirmar a identidade dos quatro isolados virais ocorrentes nas videiras em São Paulo e o relacionamento existente entre esses isolados e o GFkV, foi aplicado o teste TAS-ELISA, utilizando-se anti-soro comercial contra o GFkV (Agritest, Bari-Valenzano, Italia) e empregando-se o procedimento desenvolvido por Boscia et al. (1995). Realizouse, em menor escala, o DAS-ELISA, utilizando anti-soro contra o GFkV (Bioreba, Suíça) com o protocolo adotado por Ramel et al. (1993).

Os testes sorológicos foram efetuados, entre junho/ 1999 e outubro/2001, no Laboratório de Virologia Vegetal do Departamento de Entomologia, Fitopatologia e Zoologia Agrícola da Escola Superior de Agricultura "Luiz de Queiroz", ESALQ/USP, Piracicaba, SP.

Todas as plantas usadas nos testes sorológicos foram, inicialmente, enxertadas na videira indicadora 'Rupestris du Lot', sendo mantidas em casa de vegetação ou em canteiros do Centro de Pesquisa e Desenvolvimento de Fitossanidade, Setor de Virologia, do Instituto Agronômico de Campinas (IAC). Essas plantas infetadas, pertencentes a diferentes cultivares, eram procedentes de diversas áreas vitícolas do Estado de São Paulo, tais como Atibaia, Biritiba Mirim, Capão Bonito, Itupeva, Jales, Jundiaí, Pilar do Sul, São Miguel Arcanjo, São Roque, Tupi Paulista e Vinhedo.

As fontes de antígeno para o teste foram tecidos de folhas jovens, tenras e aclorofiladas da brotação de primavera e de tecidos obtidos mediante raspagem do câmbio, após retirada da casca, de ramos dormentes ou próximos da dormência.

Para o teste TAS-ELISA, placas de poliestireno (Corning ou Castor) foram submetidas a uma cobertura com $200 \mu \mathrm{l}$ de anti-soro policlonal, diluído a 1:1.000 em tampão carbonato 0,05 M, pH 9,6 e incubadas a $37{ }^{\circ} \mathrm{C}$ durante $2 \mathrm{~h}$. Após lavagem (três vezes com tampão PBST, pH 7.4, com intervalo de $3 \mathrm{~min})$, as amostras, diluídas a 1:15 (p/v) em tampão Tris- $\mathrm{HCl} 0,5 \mathrm{M}, \mathrm{pH} 8,2$, contendo $\mathrm{NaCl}$ a $0,8 \%$ (p/ v), PVP 40.000 a 2\% (p/v), PEG 6000 a $1 \%$ (p/v), $\mathrm{NaN}_{3}$ a $0,02 \%(\mathrm{p} / \mathrm{v})$ e Tween 20 a $0,05 \%(\mathrm{v} / \mathrm{v})$, foram adicionadas aos poços $(200 \mu \mathrm{l})$ das placas e incubadas por $2 \mathrm{~h}$ a $37^{\circ} \mathrm{C}$. Seguiram-se descarte, nova lavagem e adição de $200 \mu \mathrm{lde}$ anti-soro monoclonal (1:1.000) em tampão conjugado, constituído de PBS-T, pH 7,4, contendo 2\% de PVP 40.000 $(\mathrm{p} / \mathrm{v})$ e $0,2 \%$ de BSA (p/v), com incubação por $2 \mathrm{~h}$ a $37^{\circ} \mathrm{C}$. Após nova lavagem, adicionaram-se $200 \mu \mathrm{l}$ do conjugado de anti-soro monoclonal com fosfatase alcalina, diluído 1:1000 em tampão conjugado. Após incubação por $2 \mathrm{~h}$ a $37^{\circ} \mathrm{C}$, seguida de lavagem, colocaram-se $200 \mu \mathrm{l}$ de substrato $(\rho-$ fosfato de nitrofenil, Sigma N-9389, $1 \mathrm{mg} / \mathrm{ml}$ em dietanolamina 10\%, pH 9,8). Quando necessária, a reação foi paralizada pela adição de $50 \mu \mathrm{l}$ de $\mathrm{NaOH} 3 \mathrm{M}$.

A absorbância a $405 \mathrm{~nm}$ foi registrada em um leitor de ELISA ( $\Sigma 960$, Metertech, Taiwan). Uma amostra foi considerada positiva quando o valor da absorbância foi três vezes superior ao valor da absorbância da amostra de planta sadia. Os valores foram obtidos, em média, de 1 a $3 \mathrm{~h}$ de 
Identificação sorológica do vírus do mosaico das nervuras da videira...

TABELA 1 - Valores médios de absorbância $\left(\mathrm{A}_{405}\right)$ obtidos por TAS-ELISA para amostras infetadas por quatro isolados do vírus do mosaico das nervuras da videira (Vitis spp.), testados com um anti-soro contra o Grapevine fleck virus (GFkV) (Agritest), em duas repetições por planta. São Paulo, 1999-2000

\begin{tabular}{|c|c|c|c|}
\hline \multirow[b]{2}{*}{ Variedade e procedência** } & \multirow{2}{*}{$\begin{array}{c}\text { Isolado } \\
\text { viral** }\end{array}$} & \multicolumn{2}{|c|}{ Absorbância } \\
\hline & & $\begin{array}{c}\text { Folhas } \\
\text { novas }\end{array}$ & $\begin{array}{c}\text { Ramos } \\
\text { dormentes }\end{array}$ \\
\hline Isabel (SR) & $\mathrm{C}$ & 0,877 & 0,330 \\
\hline Niagara Rosada (JD) & $\mathrm{C}$ & 1,073 & 0,477 \\
\hline Seibel 2 (SR) & $\mathrm{C}$ & 0,984 & 0,654 \\
\hline Red Globe (SMA) & I & 0,768 & 0,376 \\
\hline Itália (IT) & I & 1,170 & 0,732 \\
\hline Thompson Seedless (JD) & I & 0,954 & 0,436 \\
\hline Kyoho (JD) & $\mathrm{K}$ & 0,826 & 0,380 \\
\hline Kyoho (SMA) & $\mathrm{K}$ & 0,973 & 0,496 \\
\hline Kyoho Rosado (SMA) & $\mathrm{K}$ & 0,758 & 0,301 \\
\hline Italia $(\mathrm{CB})$ & $\mathrm{F}$ & 0,816 & 0,362 \\
\hline Rupestris du Lot (CP) & $\mathrm{F}$ & 0,962 & 0,448 \\
\hline Controle positivo (Agritest) & GFkV & 1,160 & 0,892 \\
\hline Controle negativo (Agritest) & Sadio & 0,058 & 0,077 \\
\hline Niagara Rosada (CP) & Sadia & 0,067 & 0,064 \\
\hline Itália $(\mathrm{CP})$ & Sadia & 0,053 & 0,063 \\
\hline Kyoho (CP) & Sadia & 0,078 & 0,068 \\
\hline Isabel (CP) & Sadia & 0,055 & 0,076 \\
\hline Seibel $2(\mathrm{CP})$ & Sadia & 0,062 & 0,059 \\
\hline Rupestris du Lot (CP) & Sadio & 0,051 & 0,060 \\
\hline
\end{tabular}

incubação do substrato no escuro a temperatura ambiente.

O procedimento adotado para o DAS-ELISA foi o recomendado pela Bioreba. Alíquotas de 200 ul de anti-soro policlonal, diluido a 1:1.000 em tampão carbonato, foram colocadas nos poços das placas de poliestireno e incubadas a $30^{\circ} \mathrm{C}$ durante $4 \mathrm{~h}$. Após lavagem, amostras foram adicionadas aos poços $(200 \mu \mathrm{l})$ e incubadas a $4-6^{\circ} \mathrm{C}$ durante a noite. Depois de lavagem, colocaram-se $200 \mu \mathrm{l}$ do anti-soro monoclonal conjugado com fosfatase alcalina, diluído a 1:1.000 em tampão de conjugado. Após incubação por $5 \mathrm{~h}$ a $30^{\circ} \mathrm{C}$, seguida de lavagem, adicionaram-se $200 \mu \mathrm{l}$ de substrato ( $\rho$-fosfato de nitrofenil, $1 \mathrm{mg} / \mathrm{ml}$ ) diluído em dietanolamina a $10 \%, \mathrm{pH}$ 9.8. A composição dos tampões, as lavagens e as demais operações para a execução do teste foram semelhantes aos adotados para o TAS-ELISA.

$\mathrm{Na}$ Tabela 1, encontram-se os resultados médios de absorbância, obtidos por TAS-ELISA, considerando amostras foliares e de ramos dormentes, separadamente, e envolvendo os quatro isolados virais.

No DAS-ELISA, as amostras constituídas por folhas jovens exibindo sintomas evidentes de mosaico das nervuras e por estacas dormentes de videiras coletadas em Julho de 2001, foram distribuídas em uma mesma placa adotando-se duas repetições. Todas as oito amostras, provenientes de duas plantas infetadas por cada um dos quatro isolados, deram reações positivas, com os valores médios de absorbância para extratos foliares variando de 0,948 a 1,507, em comparação com os valores médios obtidos para amostras de plantas sadias $(0,03)$. Os valores das absorbâncias para extratos de tecidos de floema de estacas dormentes variaram de 0,236 a 0,406.

Os resultados obtidos nos dois testes sorológicos confirmaram que o vírus que provoca o mosaico das nervuras em videiras em São Paulo possui relacionamento sorológico com o GFkV e que os quatro isolados, considerando as diferenças na sintomatologia exibida nas indicadoras, constituem-se, provavelmente, estirpes do mesmo vírus e um possível complexo do GFkV.

A ocorrência desses quatro isolados apresenta importância etiológica, contudo, somente por meio de estudos envolvendo técnicas moleculares, como o seqüenciamento do genoma viral, as distinções genéticas dos vírus poderão ser evidenciadas. Isolados do GFkV com diferenças biológicas já foram relatados anteriormente em outros países, não tendo havido, no entanto, estudos com maiores informações de suas características (Hewitt et al.,1972; Bovey, 1972; Triolo \& Materazzi, 1987).

Diante das evidências de que os quatro isolados virais são sorologicamente relacionados com o $\mathrm{GFkV}$, plantas procedentes de diferentes áreas vitícolas do estado de São Paulo foram posteriormente submetidas aos testes imunoenzimáticos. Os resultados foram positivos para todas as amostras. As variedades e o número de plantas testadas, entre parênteses, foram: Itália (5), Rubi (3), Benitaka (3), Brasil (3), Alphonse Lavallée (1), Moscatel de Hamburgo (2), Kyoho (3), Kyoho Rosado (2), Olimpia (1), Patricia (2), Patricia Branca (2), Seibel 2 (3), Isabel (3), Thompsom Seedless (2), Piratininga (2), Red Globe (3), Flame Seedless (2), Centennial Seedless (2), Niagara Rosada (5), Niagara Branca (3), IAC 138-22 (2), IAC 116-31 (2), IAC 514-6 (Maria) (2), Don Mariano (2), Kober 5BB (3) e Rupestris du Lot (3).

As plantas de variedades procedentes de cinco estados brasileiros, previamente testadas por indexação biológica, também reagiram positivamente para o GFkV. Foram as seguintes: Folha de Figo (2) e Piratininga (1) de Minas Gerais; Flame Seedless (1) e Thompson Seedless (1) do Rio Grande do Norte; Itália (2) e Red Globe (2) de Pernambuco; Riesling (2) e IAC 116-31 (2) de Santa Catarina e Benitaka (3), Brasil (2), Italia (3), Rubi (2) e Kyoho Rosado (1) do Paraná.

Plantas consideradas livres do GFkV, pela indexação biológica mediante emprego de videira indicadora e por termoterapia, apresentaram resultados negativos em ELISA. As referidas plantas pertenceram às variedades Benitaka, Isabel, Itália, Kyoho, Niagara Branca, Niagara Rosada, Patrícia, Rubi, Seibel 2, Kober 5BB e Rupestris du Lot.

Durante a execução dos testes de ELISA, foi verificado que os extratos de folhas novas, tenras e aclorofiladas da brotação de primavera, principalmente aquelas em início de desenvolvimento dos sintomas, apresentaram valores de absorbância mais consistentes do que os extratos de ramos dormentes ou próximos da dormência, sob condições 
ambientais de São Paulo. Em diversas ocasiões, testes realizados com ramos dormentes necessitaram ser repetidos. Em outros países, testes envolvendo folhas novas e ramos dormentes apresentaram resultados similares para o mesmo teste imuno-enzimático empregado neste trabalho (Boscia et al., 1995; Schieber et al., 1997). Foi também observado que folhas novas e tenras de brotação vigorosa, originada posteriormente a fase de brotação de primavera constituíramse em boas fontes de vírus, nos períodos de predomínio de temperatura amena.

Os resultados obtidos indicaram que a indexação biológica baseada na enxertia para a videira indicadora 'Rupestris du Lot' foi mais eficiente do que o ELISA, quando se empregaram extratos de ramos dormentes para a reação sorológica. Entretanto, o teste sorológico é de alto valor para as triagens de material de videira, desde que se usem amostras foliares adequadas, que só podem ser obtidas em período de crescimento inicial da videira. Para os testes de obtenção de clones sadios, considera-se ainda indispensável o emprego de videira indicadora.

\section{AGRADECIMENTOS}

Os autores expressam os seus agradecimentos ao Dr. Elliot W. Kitajima, do Dept. Entomologia, Fitopatologia e Zoologia Agrícola, ESALQ, USP, Piracicaba, SP., pela revisão do manuscrito e sugestões apresentadas. Também agradecem ao José Edivaldo Buriolla (ESALQ), pelo apoio técnico.

\section{REFERÊNCIAS BIBLIOGRÁFICAS}

BOSCIA, D., ELICIO, V., SAVINO, V. \& MARTELLI, G.P. Production of monoclonal antibodies to grapevine fleck virus. Plant Pathology 44:160-163. 1995.

BOSCIA, D., MARTELLI, G.P., SAVINO, V. \& CASTELLANO, M.A. Identification of the agent of the grapevine fleck disease. Vitis 30:97-105. 1991.

BOVEY, R. Un virus latent dans le Chasselas. In: Conférence du Groupe International d'Étude des Virus et des Maladies à Virus de la Vigne, 4. Annales de Phytopathologie, Numéro hors série, 1972. pp.31-34.
KUHN, G.B. Manchas das nervuras da folha da videira (Vitis spp.), doença constatada no Rio Grande do Sul. Fitopatologia Brasileira 17:435-440. 1992.

KUNIYUKI, H. \& COSTA, A.S. Incidência de vírus da videira em São Paulo. Fitopatologia Brasileira 12:240-245. 1987.

KUNIYUKI, H. \& COSTA, A.S. Mosaico das nervuras, uma virose da videira em São Paulo. Summa Phytopathologica 20:152157. 1994.

KUNIYUKI, H. \& COSTA, A.S. Ocorrência de mais um isolado do vírus do mosaico das nervuras da videira que não causa sintomas no porta-enxerto Kober 5BB. Fitopatologia Brasileira 20:618-622. 1995.

HEWITT, W.B., GOHEEN, A.C., CORY, L. \& LUHN, C.F. Grapevine fleck disease, latent in many varieties, is transmitted by graft-inoculation. In: Conférence du Groupe International d' Étude des virus et des Maladies à Virus de la Vigne, Colmar, 1970. Annales de Phytopathologie, Numéro hors série, 1972. pp.43-47.

MARTELLI, G.P. Grapevine Virology Highlights 1997-2000. In: Meeting of the International Council for the Study of Viruses and Virus-like Diseases of the Grapevine, 13, Extended Abstracts. Adelaide, University of Adelaide, 2000. pp.1-5.

RAMEL, M.E., SERRANT, P. \& GUGERLI, P. Monoclonal and polyclonal antibodies for the detection of grapevine fleck associated virus. In: International Council for the Study of Viruses and Virus-like Diseases of the Grapevine, 11. Extended Abstracts. Montreux, 1993. pp.161-163.

SABANADZOVIC, S., SALDARELLI, P. \& SAVINO, V. Molecular diagnosis of Grapevine fleck virus. Vitis 35:137.140. 1996.

SABANADZOVIC, S., ABOU-GHANEM, N., SALDARELLI, P. \& MARTELLI, G.P. Grapevine fleck virus as the type species of a possible new genus of plant viruses. In: International Council for the Study of Viruses and Virus-like Diseases of the Grapevine, 13. Extended Abstracts. Adelaide, 2000. p. 70.

SCHIEBER, O., SEDDAS, A., BELIN, C. \& WALTER, B. Monoclonal antibodies for detection, serological characterization and immunopurification of Grapevine fleck virus. European Journal of Plant Pathology 103:767-774. 1997.

TRIOLO, E. \& MATERAZZI, A. La "maculatura infettiva" della vite:influenza di isolati diversi sull'attitudine alla propagazione vegetativa di Vitis rupestris "St. George". La Recherche Agronomique in Suisse 26:320-324. 1987. 